\title{
AIAA-98-3518 \\ Propellant Management and \\ Conditioning Within the X-34 Main \\ Propulsion System
}

T. M. Brown, J. P. McDonald, A. Hedayat

and K. C. Knight

Propulsion Department

Sverdrup Technology Inc., MSFC Group

Huntsville, AL

R. H. Champion, Jr.

Marshal Space Flight Center

Huntsville, AL

\section{4th AIAA/ASME/SAE/ASEE Joint Propulsion Conference \& Exhibit July 13-15, 1998 / Cleveland, OH}




\title{
PROPELLANT MANAGEMENT AND CONDITIONING WITHIN THE X-34 MAIN PROPULSION SYSTEM
}

\author{
T. M. Brown, J. P. McDonald, A. Hedayat" and K. C. Knight ${ }^{\ddagger}$ \\ Propulsion Department \\ Sverdrup Technology, MSFC Group \\ Huntsville, AL 35806 \\ R. H. Champion, Jr. $\S$ \\ Propulsion Laboratory \\ NASA Marshall Space Flight Center \\ Huntsville AL 35812
}

\begin{abstract}
The X-34 hypersonic flight vehicle is currently under development by Orbital Sciences Corporation (Orbital). The Main Propulsion System (MPS) has been designed around the liquid propellant Fastrac rocket engine currently under development at NASA Marshall Space Flight Center. This paper presents analyses of the MPS subsystems used to manage the liquid propellants. These subsystems include the propellant tanks, the tank vent/relief subsystem, and the dump/fill/drain subsystem. Analyses include LOX tank chill and fill time estimates, LOX boil-off estimates, propellant conditioning simulations, and transient propellant dump simulations.
\end{abstract}

\section{INTRODUCTION}

The $\mathrm{X}-34$ vehicle is to be capable of hypersonic flight (Mach 8) at altitudes of 250,000 feet. The X34 vehicle Main Propulsion System (MPS) utilizes the Liquid Oxygen (LOX) and kerosene (RP-1) Fastrac rocket engine currently under development at NASA Marshall Space Flight Center (MSFC). A detailed overview of the entire X-34 propulsion system has been provided by Sgarlata and Winters.' The X-34 vehicle will be launched from the bottom of an L1011 aircraft after being carried to an altitude of 38,000 feet. The horizontal flight of the X-34 vehicle, coupled with many aggressive operational goals, have created several challenges not normally considered in conventional vertical flight rockets.

\footnotetext{
* Engineer, Member ALAA.

* Lead Engineer, Member AIAA.

$\S$ X-34 MPS Product Development Team Lead, Member AIAA.
}

This Paper is declared a work of the U.S. Government and is not subject to copyright protection in the United States.
Detailed analyses of the MPS subsystems are required initially as design inputs, and later for design validation and verification. This paper presents MPS subsystem analysis overviews dealing with the management of propellants during X-34 ground operations, captive carry prior to launch, and flight abort scenarios. Propellant feed and pressurization systems are covered in detail by McDonald et al., ${ }^{2}$ and Hedayat et al., ${ }^{3}$ respectively.

The X-34 MPS propellant management system is made up of three subsystems. The propellant tanks store the propellant during X-34 operations, control propellant orientation, and limit Center of Gravity (CG) shift during flight. The tank vent/relief system controls tank pressures during fill, propellant conditioning procedures, and in the event of pressurization system failure. The dump/fill/drain system has three functions. The system is capable of dumping propellants in the case of an aborted mission. In addition, the system is used to fill the propellant tanks prior to flight and remove residuals after flight.

The general layout of much of the X-34 MPS within the X-34 vehicle is presented in Figure 1 . Figure 2 is an abbreviated MPS schematic. LOX is stored in two compartmentalized tanks. The LOX vent is connected to the forward end of the front LOX tank. The LOX dump/fill/drain system is connected to the aft end of the rear LOX tank. RP-1 is stored in a single compartmentalized tank. Like the LOX tanks, the RP-I tank has check valves that control the flow direction of liquid and gas. Liquid RP-1 is allowed to flow toward the rear of the tank and gaseous ullage is allowed to flow toward the front of the tank. The RP-1 system has a common feed, dump, drain and fill line for much of the vehicle length, with separate lines and valves at the tank and the aft end. The RP-1 vent system is connected to the front most compartment of the tank. 
Aggressive operational goals complicate the design and analysis of the X-34 MPS. The vehicle must be capable a 24 hour flight turnaround. Operational timelines designed to achieve this goal set aside 60 minutes for the LOX tanks to be chilled and filled with $21,050 \mathrm{lbm}$, and 45 minutes for the RP-1 tank to be filled with $9,350 \mathrm{lbm}$. The LOX tank vent will be closed during the 30 minute ascent phase of captive carry. Therefore, the heat load induced pressure rise must not be sufficient to overpressurize the tank. The total captive carry time will be 2.5 hours. LOX boil-off during this period must be minimized to maximize total usable propellant as well as powered flight duration. The in flight dump systems must be capable of expelling $95 \%$ of the initial propellant load in 300 seconds. Also, all systems must be two fault tolerant to a catastrophic failure while on the ground or connected to the L1011 carrier vehicle.

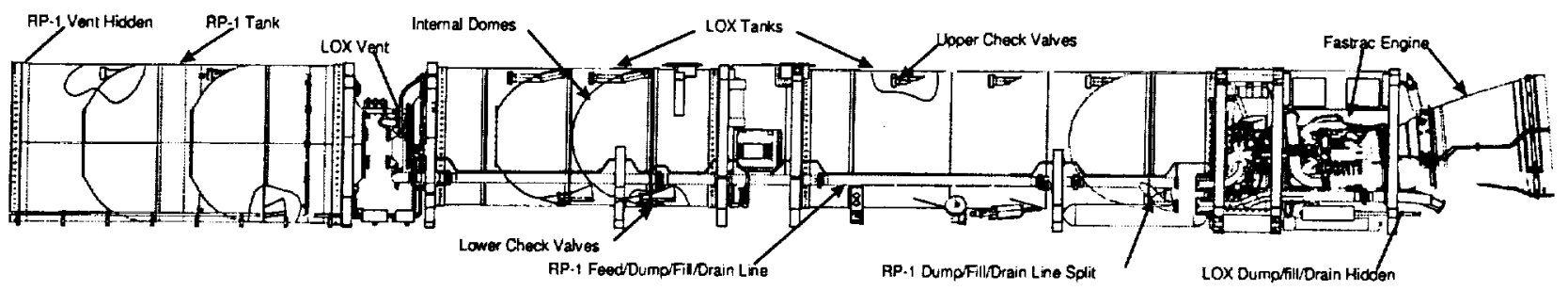

Figure 1. MPS Layout Within the X-34 Vehicle

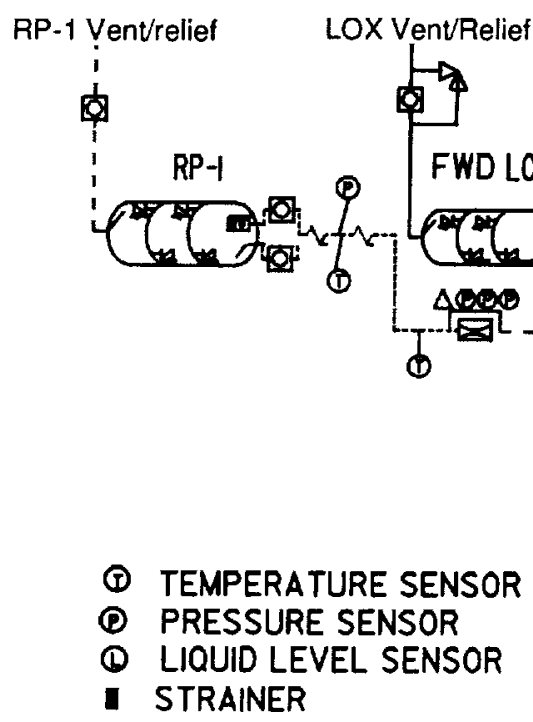

Figure 2. Schematic of the Propellant Management Subsystems

\section{LIOUID OXYGEN TANK CHILL AND FILL ANALYSIS}

The X-34 LOX tanks must be chilled and filled in 60 minutes to support the X-34 operations timeline. The primary MPS constraint on the LOX chill and fill time is the Gaseous OXygen (GOX) vent velocity limit. Velocity limits are applied to reduce the possibility of chemical reaction due to particle impingement within the aluminum vent system components. A design GOX vent velocity limit of 100 meters/second has been considered for low pressure (<30 psia) operations such as chill and fill. Higher pressure operations (50 - 75 psia), such as vent after LOX tank lock-up for ascent to 38,000 feet altitude, are limited to 45 meters/second. This lower 
vent velocity limit is achieved by the addition of an exit orifice to the vent system. The exit orifice chokes the GOX flow and limits the velocity upstream. The inside diameter of the LOX vent system is 2.245". Assuming the GOX temperature will be a maximum of $70 \mathrm{~F}$, the low pressure maximum vent velocity limits the maximum vent mass flow rate to $0.7 \mathrm{lbm} / \mathrm{sec}$. This maximum vent mass flow rate limits the chill flow rate and thus influences the minimum LOX chill and fill time. The following analysis provides an estimate of the minimum LOX chill and fill time, accounting for LOX vent mass flow limitations.

The X-34 LOX tanks are divided into seven compartments. The compartments are separated by internal domes with upper and lower check valves. The lower check valves allow fluid flow toward the rear and the upper check valves allow fluid flow toward the front. The LOX tanks are filled from the rearmost compartment through the dump/fill/drain line. The compartments are filled one at a time, spilling through the upper check valves. This procedure is illustrated in Figure 3. Figure 3a illustrates the filling of the aft most compartment, and Figure $3 b$ illustrates the spilling over of LOX from the aft most compartment to its nearest neighbor.

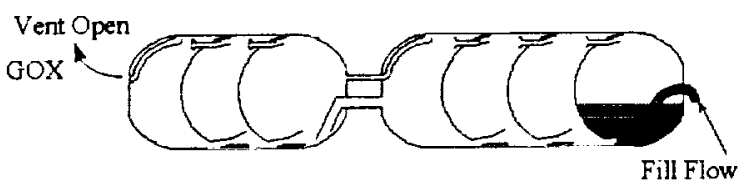

$3 a$

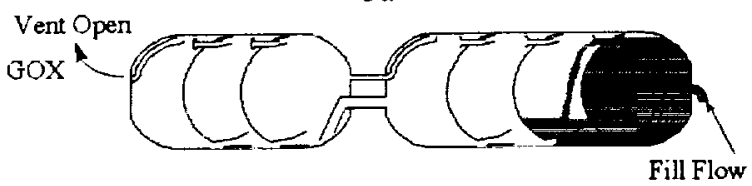

$3 \mathrm{~b}$

Figure 3. Illustration of the LOX Tank Fill Procedure

Several simplifying assumptions have been made to estimate the minimum LOX chill and fill time. The rate of conduction through the thin (0.125") tank walls is assumed to be small relative to the chill rate. Heat is assumed to be removed only by boiling LOX, not by heat transfer to the cold oxygen vapor. Also, the heat transfer coefficient between the tank walls and LOX is assumed to be large. The minimum chill and fill time procedure is designed such that the rising LOX contacts warm metal at a rate described by the following equation,

$$
\begin{gathered}
M d \operatorname{dot}(A l \text { contact }) * C p(A l) * \Delta T / h f g(L O X) \\
=0.7 \mathrm{lbm} / \mathrm{sec}(G O X)
\end{gathered}
$$

insuring that the maximum GOX flow rate through the vent is $0.7 \mathrm{lbm} / \mathrm{sec}$. Here, $M d o t(A l$ contact) is the mass rate at which the aluminum is being chilled, $C p(A l)$ is the specific heat of aluminium, $\Delta T$ is the temperature differential between the LOX and the hot tank, and $h f g(L O X)$ is the heat of vaporization for LOX.

Every term of the governing equation is known and assumed constant except the $M d o t(A l$-contact). This term is actually a non-linear function of the fill rate, and through tank geometry, the fill level. At a constant flow rate, $M \operatorname{dot}(A l$-contact) is much higher when the compartment is nearly empty or full than it is when the compartment is about half full. This dependence of $M \operatorname{dot}(A l$-contact) on the compartment fill level is a function of individual compartment geometry. Geometries of the LOX tanks and the individual compartments are also known. Therefore, the only remaining unknown is the maximum LOX chill/fill rate. Figure 4 is a plot of maximum allowable LOX chill/fill rate as a function of time. The maximum LOX chill/fill rate is the rate at which the vaporized LOX will produce a GOX vent flow of $0.7 \mathrm{lbm} / \mathrm{sec}$. The maximum chill/fill rate that can be supplied by the Ground Support Equipment (GSE) is assumed to be $13 \mathrm{lbm} / \mathrm{sec}$. The initial tank temperature is assumed to be $70^{\circ} \mathrm{F}$ and the LOX temperature is assumed to be $-300^{\circ} \mathrm{F}$.

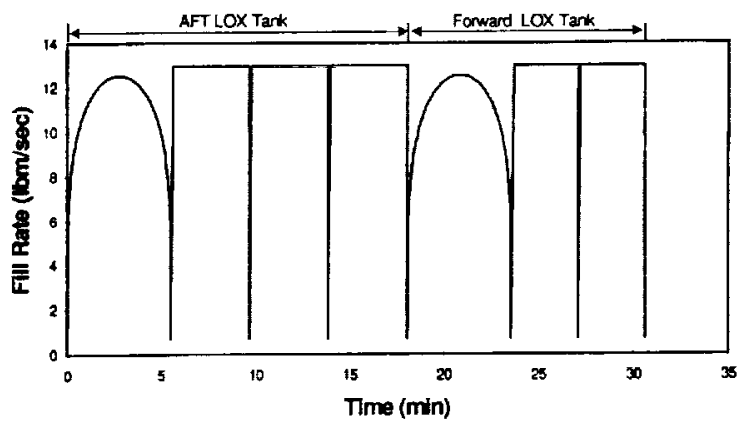

Figure 4. Maximum LOX Chill/Fill Rates as a Function of Time

Figure 4 indicates that the minimum LOX chill and fill time is 31 minutes. The humps occurring at 0 minutes and $\sim 18$ minutes correspond to the filling of the rear nearly spherical compartments of each tank. The other compartments do not exhibit this shape because the maximum allowable flow rate quickly reaches the $13 \mathrm{lbm} / \mathrm{sec}$ GSE flow rate limit. These compartments share an interior wall with previously 
chilled compartments and, therefore, can be filled at a higher rate. Figure 4 indicates that the maximum chill/fill rate is reduced to $0.7 \mathrm{lbm} / \mathrm{sec}$ at every transition between compartments. This occurs because, at the transition, the LOX will spill over into a warm compartment and immediately vaporize. In practice, cold LOX vapor passing through adjacent compartments toward the vent at the front of the forward LOX tank will cool the tank walls and minimize this effect. During LOX fill procedures the maximum pressure in the tank will be $<20$ psig (within the rear compartment). The maximum pressure differential across the internal domes will be $<2$ psi.

Figure 4 demonstrates that the MPS components and subsystems are capable of supporting the aggressive 60 minute LOX tank chill and fill planned for X-34 ground operations. This estimate does not account for a slow topping flow near the end of the fill procedure. The actual LOX fill procedure is not likely to involve continuous adjustment of the LOX flow rate and will take longer than the 31 minute minimum presented in Figure 4. In addition, the analysis presented in Figure 4 does not account for thermal induced stresses within the tanks. Chill and Fill flow limits based on thermal induced stresses will be determined through $\mathrm{LN}_{2}$ chill and fill tests.

\section{LOX TANK INSULATION AND BOIL-OFF ANALYSIS}

Boil-off analyses are performed to provide estimates of propellant loss during the captive carry phase of the X-34 flight trajectory. Heat transfer into the LOX tanks is estimated by combining a simple one dimensional conduction/convection resistance formulation with a radiative resistance model. A simplified model of the LOX tanks is considered for the radiation mode. The model assumes radiation heat transfer between the tank insulation surface and a fuselage inside surface completely enclosing the tanks. All of the tank end domes are assumed to contribute equally to the radiation heat transfer. Figure 5 illustrates the simplified model geometry assumed for radiation. The fuselage radius of 31 inches is simply an estimate.

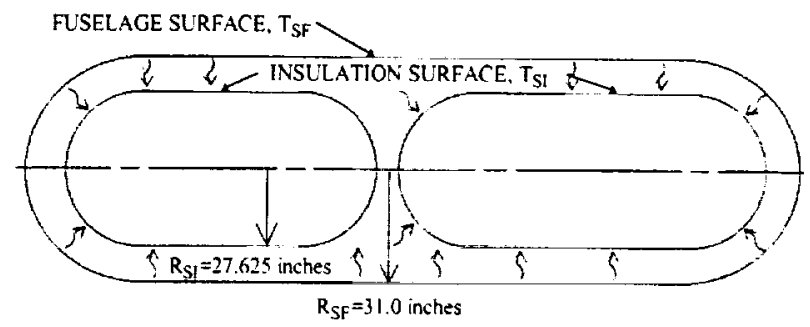

Figure 5. Simplified Model for Radiation.

In most areas, the fuselage is at a radius of more than 31 inches, making the present results conservative. Additional conservatism exists as only the forward LOX tank forward end dome contributes substantially to radiation heat transfer due to its proximity to the warmer RP-1 tank. The radiation resistance based on Figure 5 is

$$
\mathrm{R}_{\mathrm{rad}}=\frac{\frac{1-\varepsilon_{\mathrm{SF}}}{\varepsilon_{\mathrm{SF}} \mathrm{A}_{\mathrm{SF}}}+\frac{1}{\mathrm{~A}_{\mathrm{SF}}{ }^{\mathrm{F}} \mathrm{SFtoSI}}+\frac{1-\varepsilon_{\mathrm{SI}}}{\varepsilon_{\mathrm{SI}} \mathrm{A}_{\mathrm{SI}}}}{\sigma \cdot \mathrm{T}_{\mathrm{SF}}-\mathrm{T}_{\mathrm{SI}}{ }^{\prime} \mathrm{T}_{\mathrm{SF}}{ }^{2}+\mathrm{T}_{\mathrm{SI}}{ }^{2}}
$$

where $\varepsilon$ denotes emissivity, $A$ denotes area, $F$ denotes radiation view factor, $\sigma$ is the Stefan-Boltzmann constant, and $\mathrm{T}$ denotes temperature. The subscripts SF and SI refer to fuselage and tank insulation surfaces, respectively. The radiation view factor from the fuselage to insulation surface is, $\mathrm{F}_{\mathrm{SF} \text { toSI }}=$ $\mathrm{A}_{\mathrm{Sl}} / \mathrm{A}_{\mathrm{SF}}$.

Figure 6 illustrates an electrical circuit representation for heat transfer in this simplified model. For simplicity, $\mathrm{T}_{\mathrm{SF}}$ is assumed equal to $\mathrm{T}_{\text {purge, }}$ as there is no aerodynamic heating during captive carry. The convection resistance is

$$
\mathrm{R}_{\mathrm{CONV}}=\mathrm{l} /\left(\mathrm{hA}_{\mathrm{SI}}\right) \text {. }
$$

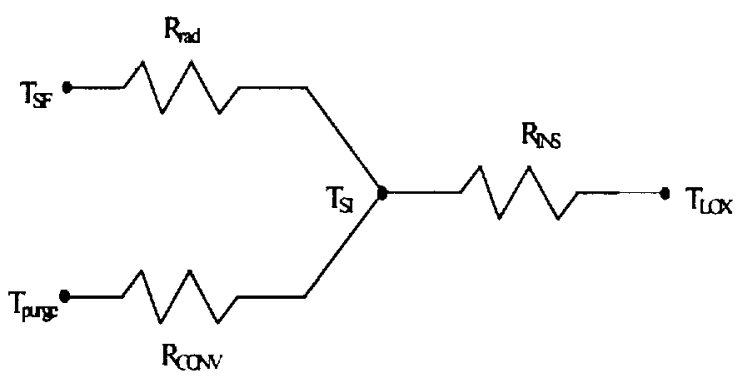

Figure 6. Electrical Circuit Representation for the Simplified Model. 
The convection heat transfer coefficient is $h=h(P$, $T_{\text {film }}$ ), where $P$ is the ambient pressure and the film temperature is $\mathrm{T}_{\text {film }}=\left(\mathrm{T}_{\text {purge }}+\mathrm{T}_{\mathrm{SI}}\right) / 2$. The conduction resistance due to the insulation is approximated as

$$
\mathrm{R}_{\mathrm{INS}}=\mathrm{dR}_{\mathrm{INS}} /\left(\mathrm{k}_{\mathrm{INS}} \mathrm{A}_{\mathrm{INS}}\right)
$$

where $d R_{\text {INS }}$ is the insulation thickness, $k_{I N S}=$ $\mathrm{k}_{\text {INS }}\left[\left(\mathrm{T}_{\mathrm{LOX}}+\mathrm{T}_{\mathrm{SI}}\right) / 2\right]$, and $\mathrm{A}_{\text {INS }}$ is the conduction area calculated halfway through the insulation thickness. The LOX temperature is assumed to be constant at $\mathrm{T}_{\mathrm{LOX}}=160^{\circ} \mathrm{R}$. The unknown $\mathrm{T}_{\mathrm{SI}}$ is solved for iteratively by guessing a value and comparing it with a value of $T_{S I}$ resulting from an energy balance at the insulation surface.

The purge temperature, $T_{\text {purge, }}$ is approximated from X-34 internal environment simulations provided by Orbital Sciences Corporation. Figure 7 presents the simulated purge temperature as a function of time. Figure 7 begins at start of the 60 minute LOX loading procedure and ends after a two and a half hour captive carry.

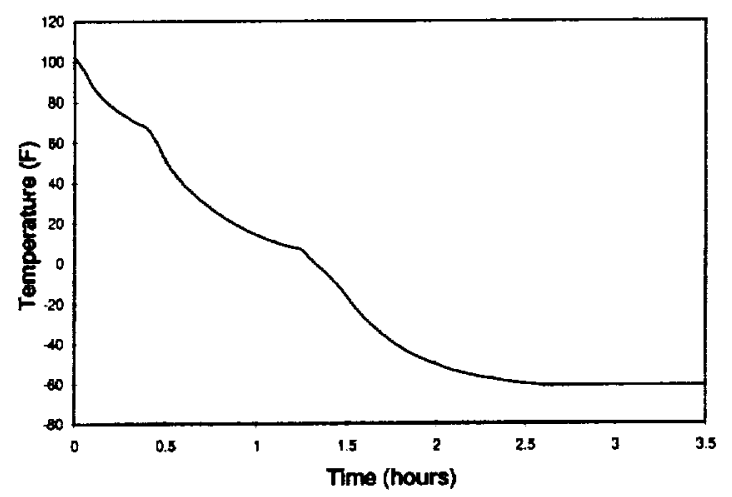

Figure 7 Simulated X-34 Internal Environment Temperature Around the LOX Tanks

Captive carry will begin at about 1 hour, at which time the LOX fill/replenish lines are disconnected. Additional heat loads due to the tank mounting skirts and tank penetrations are estimated as parallel resistances to those presented in Figure 6.

Boil-off predictions, based on the purge temperature profile presented in Figure 7, suggest that $716 \mathrm{lbm}$ of LOX will be lost during captive carry phase of the X-34 flight trajectory. The boil-off during captive carry represents $-3.4 \%$ of the LOX mass at the end of tank topping procedures.

\section{TANK VENT/RELIEF SYSTEMS}

\section{LOX Vent System Performance}

The LOX vent system is made up of 2.245 " ID aluminum and stainless steel lines, with a $2.5^{\prime \prime}$ pneumatic vent/relief valve. A secondary relief valve is mounted in a leg bypassing the 2.5 " vent relief valve. The $\operatorname{LOX}$ vent also has a removable exit orifice that limits flow velocities during high pressure vent operations. The LOX vent system has been simulated by the Generalized Fluid System Simulation Program (GFSSP). ${ }^{4}$ GFSSP is a generalized ID nodal fluid system analysis tool. For the current simulations, boundary conditions are set at the vent inlet and vent exit corresponding to different phases of operation. Branch properties within the model are, in some cases, intentionally made conservative to assure the actual system will meet MPS requirements.

There are three major demands on the LOX vent system. The pressure drop across the vent system must be minimal while expelling boil-off flow during ground operations. The flow velocities within the vent system must remain below 45 meters/second while tank pressures are above 30 psi to avoid fire risks. Also, the vent system must be capable of expelling $0.35 \mathrm{lbm} / \mathrm{sec}$ of helium at $-73 \mathrm{~F}$ or 0.49 $\mathrm{lbm} / \mathrm{sec}$ of helium at $-270^{\circ} \mathrm{F}$ with the tank pressure at or below the proof pressure of $112.5 \mathrm{psi}$. This helium flow demand only occurs in the event of pressurization system valve failures. Helium flow demands were estimated by the pressurization system model. $^{3}$

Simulation results indicate that, with the exit orifice removed, the LOX system is capable of expelling the normal ground operations boil-off flow with a minimal pressure differential $(<0.3 \mathrm{psi})$, thus allowing the lowest possible saturation temperature and the greatest LOX densification. During pre-flight ground operations, the vent exit orifice is removed because vent system pressures will remain below 30 psi greatly reducing the risk of ignition from high velocity particle impingement. The possibility of high flow velocities while system pressures are above 30 psi exists during vent operations at altitude. After ground operations are complete, the LOX vent exit orifice is replaced. Simulation results indicate that a 1" sharp edged orifice at the vent exit limits flow velocities within the valve body to a maximum of 33 meters/second. The LOX vent exit orifice should be constructed of an ignition resistant material such as Inconel 718 .

The possibility of tank overpressurization exists in the event of a pressurization system failure. 
GFSSP simulation results indicate that the LOX vent system is capable of expelling $0.52 \mathrm{lbm} / \mathrm{sec}$ of helium at $-70 \mathrm{~F}$ while the tank pressure is at $112 \mathrm{psi}$

The main vent/relief leg is capable of preventing overpressurization due to cryogenic lock-up. However, a two fault tolerance requirement necessitates a secondary passive relief within the system. Simulations suggest that a secondary relief valve with a full flow ESEOD larger than 0.4" is sufficient to prevent overpressurization due to cryogenic lock-up even with the exit orifice in place.

\section{$\underline{\text { RP-1 Vent System Performance }}$}

The RP-1 vent system is made up of corrugated metal flex line and an identical 2.5 " vent relief valve to that used in the LOX system. The RP-1 vent system has also been simulated by GFSSP.' Boundary conditions are set at the vent inlet and vent exit corresponding to different phases of operation.

The most demanding function of the RP- 1 vent system is to prevent tank overpressurization in the event of a pressurization system failure. The vent system must be capable of expelling $0.10 \mathrm{lbm} / \mathrm{s}$ of helium at $-97^{\circ} \mathrm{F}$ or $0.15 \mathrm{lbm} / \mathrm{s}$ of helium at $-283^{\circ} \mathrm{F}$ from the tank while the tank is at or below its proof pressure of 150 psi. Helium flow demands are estimated by the pressurization system model. ${ }^{3}$

GFSSP results indicate that the RP- 1 vent system is capable of expelling $0.977 \mathrm{lbm} / \mathrm{sec}$ of helium at 70 ${ }^{\circ} \mathrm{F}$. Therefore, the system can easily meet the flow demands of a pressurization system failure.

\section{PROPELLANT CONDITIONING ANALYSIS}

\section{LOX Conditioning Analysis}

Tank pressure affects the LOX condition by altering the bulk saturation temperature. After the final LOX tank filling operation, tank pressure will depend on the atmospheric pressure at the vent exit and the pressure drop over the vent lines. In addition, the LOX vent line will be closed during the L-1011 taxi and ascent stage of the captive carry $(\sim 30 \mathrm{~min}$.). During this time the tank pressure must remain below $75 \mathrm{psi}$ to avoid venting through the pressure relief valve. After the lock-up phase, the tank pressure is controlled from $\sim 11.3 \mathrm{psi}$ to $20 \mathrm{psi}$ by the vent system. This procedure allows LOX to boil-off and conditions the propellant to a suitable temperature for engine start.

\section{LOX Tank Lock-Up Model}

The oxygen in the LOX tanks will not be in thermal equilibrium during the vent lock-up period. The average ullage gas temperature will be higher than the liquid temperature. A simplified nonequilibrium model of the lock-up period has been developed. The model is based on conservation of energy with a multiple bulk mass approach. Figure 8 illustrates the model.

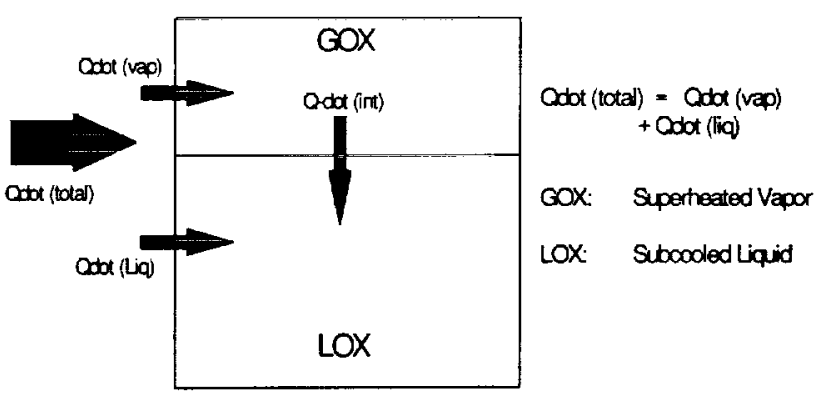

Figure 8. Non Phase Equilibrium Tank Pressure Model.

The tank experiences a heat load due to the temperature differential from the outside environment to the inside of the tank. The GOX ullage receives more energy per unit mass due to its low density. The ullage gas temperature and the tank pressure quickly rise. With this increase in pressure, the fluids in the tank do not remain at their initial saturated conditions. The ullage gas becomes a superheated vapor and the LOX becomes a subcooled liquid. Therefore, simplified state equations are capable of predicting the fluid properties. The non-equilibrium model treats the vapor and the liquid as individual bulk masses. Heat transfer from the external environment to the ullage gas, from the external environment to the liquid, and from the ullage gas to the liquid are all considered. The total heat load into the tank, Qdot(total), is estimated by the boil-off model. Individual heat transfer rates are estimated based on temperature differential, contact surface area, insulation resistance, and the appropriate heat transfer coefficient.

The non-phase equilibrium model has been tested against experimental data from an LN2 tank lockup experiment conducted at NASA MSFC. The variables used in the model were generally derived from tank geometry, fill level, and the measured heat load. The only remaining inputs were the internal heat transfer coefficients. These coefficients were adjusted until the simulated pressure rise and LN2 temperature rise matched the measured profiles. The internal heat transfer coefficients were then applied to the X-34 tank lock-up simulation. 


\section{Controlled Vent Model}

A controlled vent model has been developed to simulate LOX conditioning procedures during captive carry. The controlled vent model contains the aforementioned lock-up model to simulate closed vent conditions and has an additional routine that simulates the open vent condition. The open vent routine is activated when the simulated tank pressure reaches 20 psi. At this point mass is expelled and a new pressure is calculated. Vent flow rates are calculated as a function of tank pressure and gas temperature. The functional relationship was developed using the Generalized Fluid System Simulation Program. ${ }^{4}$ After the tank pressure reaches the saturation pressure of the LOX, any mass expelled through the vent is subtracted from the liquid mass. The corresponding heat of vaporization is also subtracted from the liquid and the bulk LOX temperature drops. This process continues until the tank pressure reaches 13 psi. Next, the lock-up routine is reactivated and the process starts over.

\section{LOX Conditioning Simulations}

Heat loads used in the lock-up and controlled vent simulation are estimated by the boil-off model using internal environment simulations provided by Orbital. A heat load of $\sim 9.8 \mathrm{Btu} / \mathrm{sec}$ is applied to the tank in the lockup simulation. This heat load corresponds to the average load during the 30 minute lock-up period. Figure 9 presents LOX tank pressure rise as a function of time.

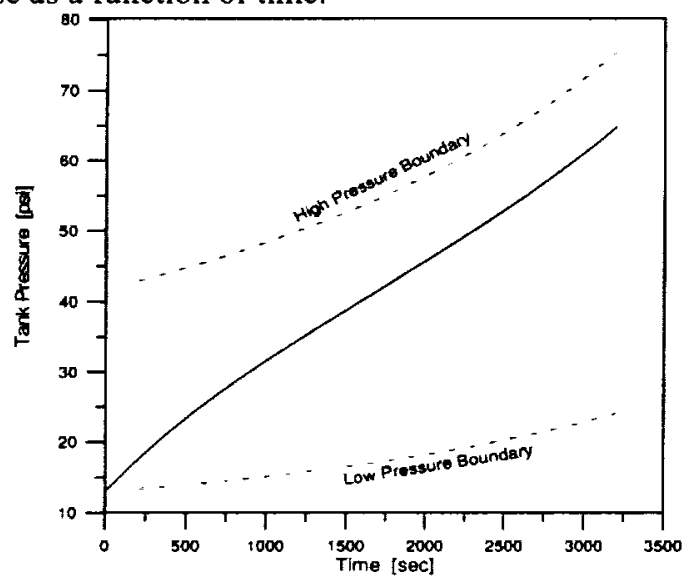

Figure 9. LOX Tank Lock-Up Simulation Results

The dashed lines on the plot represent the highest and lowest expected pressures. The high pressure curve is calculated by forcing the ullage temperature to the external environment temperature and allowing the remaining heat to raise the LOX temperature. The low pressure curve is calculated by adding all the heat to the LOX, raising its temperature, and assuming the tank contents are in thermal equilibrium. The solid curve represents the simulation results. As expected the simulation predicts pressures between the high and low pressure boundaries. These results indicate that it will take at least $3000 \mathrm{sec}$ for the tank pressure to reach 75 psi.

The controlled vent simulation includes an initial 30 minute lock-up followed by a two hour controlled vent procedure. A heat load of $\sim 7.3 \mathrm{Btu} / \mathrm{sec}$ is applied and the tank pressure is maintained between 13 and 20 psi during the two hour controlled vent procedure. Figure 10 presents the simulated tank pressure, LOX temperature and LOX mass during the entire 2.5 hour captive carry. The lock-up portion of the simulation is identical to the first 1800 seconds of Figure 9.

Figure 10 indicates that the tank pressure will rise to 43 psia and the LOX temperature will rise to $162.2^{\circ} \mathrm{R}$ during the 1800 second lock-up portion of captive carry. Results also indicate that a controlled vent pressure band of 13 psia to 20 psia will result in LOX temperatures between 160 and $161^{\circ} \mathrm{R}$ during the LOX conditioning phase of captive carry. The current simulation cycles the vent/relief valve seven times during the 2.5 hour captive carry.

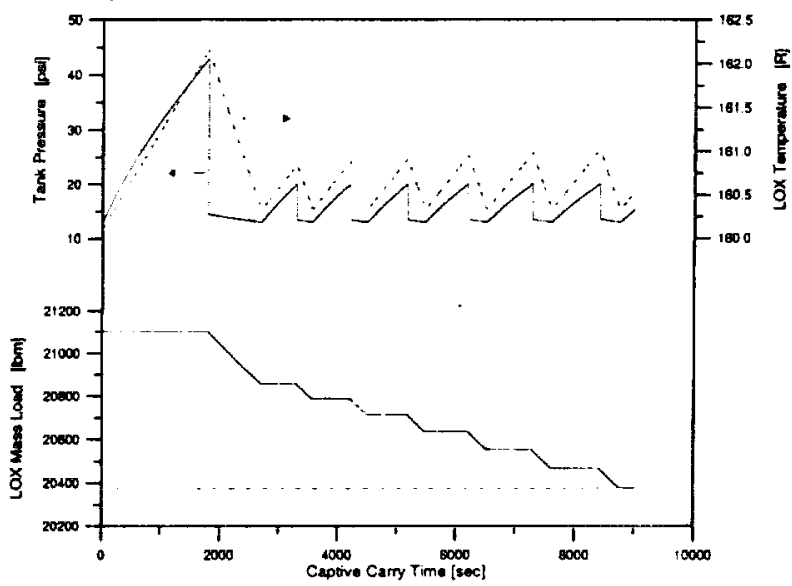

Figure 10 LOX Tank Lock-Up and Controlled Vent simulation During Captive Carry

It is interesting to note that the pressure drop during an open vent period exhibits two distinct slopes. The abrupt pressure drop that occurs immediately after the vent valve opens is due to the expulsion of hot ullage gas. The gradual pressure drop that occurs next is due to the expulsion of vaporized LOX produced as the liquid is conditioned to a lower temperature. Simulation results indicate that, during each cycle, conditioning begins to occur 
as the tank pressure drops below 13.5 psi. Conditioning continues until the tank pressure drops to 13 psi when the vent valve is closed again. Therefore, the pressure sensor providing the controller feedback should have a minimum reproducibility within 0.5 psi. A reproducibility of \pm $0.5 \mathrm{psi}$ will result in $\sim 0.6^{\circ} \mathrm{R}$ error at the end of each conditioning cycle.

The results presented in Figure 10 are calculated assuming a single bulk liquid mass and single fluid properties. In reality, LOX temperatures will vary in different sections of the tank. Therefore, results presented in Figure 10 only provide a general representation of the condition process. The LOX tank system is divided into seven compartments. The ullage gas can move forward toward the tank vent through check valves at the top of each internal tank dome. These check valves will have associated pressure drops, causing each compartment to be conditioned to a slightly different pressure. The total pressure drop from the rearmost compartment to the front compartment is estimated to be $\sim 1$ psi. In addition, the liquid head within the tank creates a pressure differential of $\sim 2.2 \mathrm{psi}$. Together, these pressure differentials may result in a total temperature variation of $\sim 3.2^{\circ} \mathrm{R}$ within the tank.

The uncertainty in tank pressure measurement will add an additional $\pm 0.5 \mathrm{psi}$ to the $3.2 \mathrm{psi}$ pressure differential across the tank. Tank pressure sensors are in the vent line upstream of the vent valve. Measured pressures correspond to the condition of the LOX at the liquid surface of that compartment and the low end of the 3.2 psi pressure differential across the tank. The saturation pressure of LOX at $160^{\circ} \mathrm{R}$ is $12.9 \mathrm{psi}$. Therefore, the $5^{\circ} \mathrm{R}$ LOX temperature variation within the tank will be centered at $160^{\circ} \mathrm{R}$, if the front compartment is conditioned to .11 .3 psi. A final vent cycle must be commanded at the end of captive carry to achieve this condition immediately prior to tank pressurization to the engine run condition. The resulting LOX temperature range at the end of captive carry will be $-160 \pm 2.5^{\circ} \mathrm{R}$. Figure 11 illustrates the compilation of tank pressure variations and pressure sensor error.

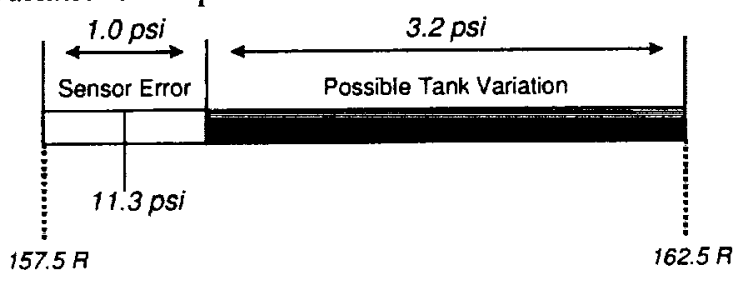

Figure 11 Compilation of Tank Pressure Variation and Sensor Error
This temperature range falls within the current required Fastrac engine start/run box range of $160 \pm 3$ ${ }^{\circ} \mathrm{R}$.

\section{RP-1 Temperature at X-34 Drop Analysis}

Bulk RP-1 temperature must fall within a set (Start Box) range at engine start and must remain within a tighter (Run Box) band during engine main stage burn. X-34 internal compartment temperatures vary at different altitudes during captive carry. Changes in ambient ground temperatures prior to flight also influence the compartment temperature profiles.

RP-1 temperatures at the end of captive carry are estimated using a bulk mass formulation and X-34 internal environment temperature simulations supplied by Orbital. Figure 12 presents the internal environment temperatures simulated for hot and cold day extremes. These curves are averages of the results for two areas that encompass the region around the RP-1 tank.

The profiles presented in Figure 12 begin at initial X-34 roll out and connection to the L1011. The RP-1 fill procedure begins at 1 hour along with power connection and initiation of the conditioned vehicle purge. LOX loading begins at 3 hours and L1011 takeoff occurs shortly after 4 hours.

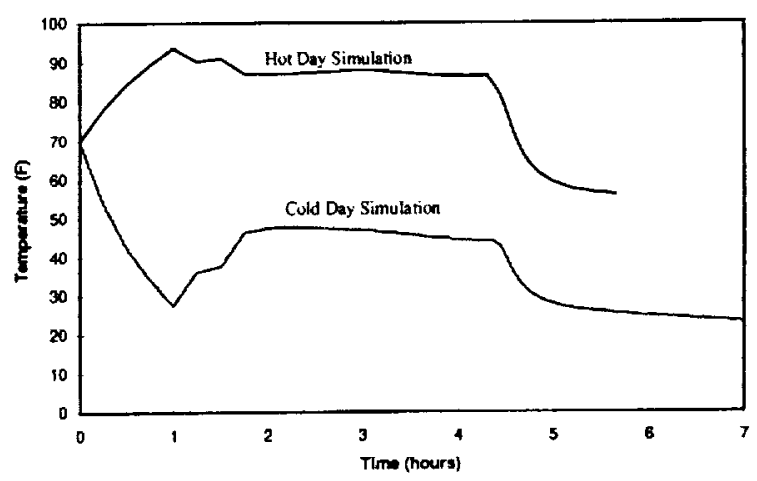

Figure 12 Simulated X-34 Internal Environment Temperature Around the RP-1 Tank

Results from the bulk mass formulation suggest that the RP-1 temperature at X-34 drop is most strongly affected by the initial RP-1 loading temperature. Vehicle internal environment temperature excursions have only a moderate effect. Figure 13 presents the estimated bulk RP-1 temperature at X-34 drop as a function of the RP-1 temperature at loading. The upper curve represents the results for the hot day extreme and the lower curve represents the results for the cold day extreme. 
The horizontal lines represent the upper and lower temperature bounds of the Fastrac engine start/run box.

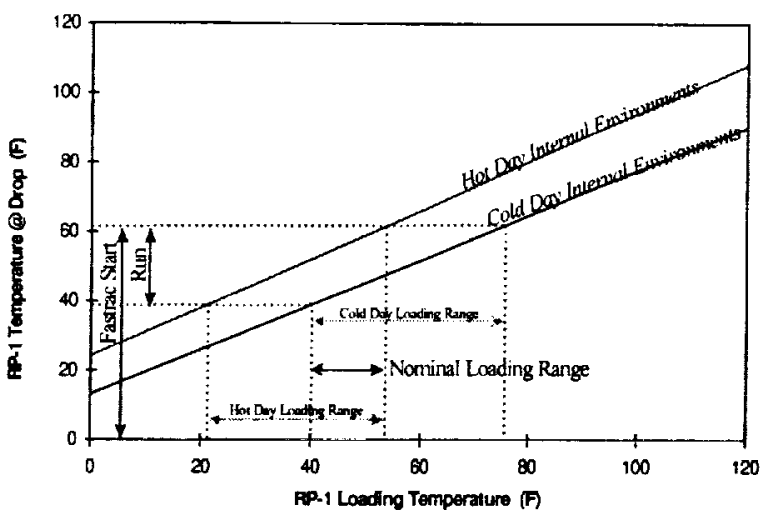

Figure 13 RP-1 Temperature at X-34 Drop

Constraining the RP-1 loading temperature between $40^{\circ} \mathrm{F}$ and $54^{\circ} \mathrm{F}\left(47 \pm 7^{\circ} \mathrm{F}\right)$ results in a temperature range of $39^{\circ}-63^{\circ} \mathrm{F}\left(51 \pm 12^{\circ} \mathrm{F}\right)$ at $\mathrm{X}-34$ drop. Maintaining the RP-1 at a single loading temperature, regardless of the vehicle internal environment temperature, will result in a $\pm 7^{\circ} \mathrm{F}$ band in the RP-1 temperature at drop. The simulated X-34 internal environment temperature profiles indicate that temperatures outside the RP-I tank will always be above the freezing point of RP-1 $\left(\sim-40^{\circ} \mathrm{F}\right)$. Therefore, localized freezing near the tank walls is not an issue.

\section{PROPELLANT DUMP SYSTEM SIMULATION}

X-34 dump system analysis was conducted in two phases. First, the LOX and RP-1 dump systems were modeled by the GFSSP. ${ }^{4}$ The GFSSP models were used to simulate steady dump flow performance at various operating conditions and the results were used to develop functional descriptions of the system performance. Next, the functional descriptions were added to a transient model that accounts for changing tank pressures and changing exit pressure as the vehicle altitude is decreased. The transient model was coupled with six degrees of freedom X-34 abort trajectory simulations provided by Orbital.

\section{LOX Dump System Model}

The LOX dump system is primarily constructed of 3.834" ID line. The major components consist of a 4" pneumatic valve and a Bernoulli type flow meter. The steady flow operation of the LOX dump system has been simulated by the GFSSP. Boundary conditions are set corresponding to varying tank pressure and X-34 altitude during the X-34 abort trajectory. In some cases branch properties within the model are intentionally made conservative to ensure the actual system will meet the flow requirements.

Early LOX dump simulations indicated that the LOX was beginning to vaporize within the LOX dump flow meter. Vaporization occurred within the LOX dump system because the dump exit pressure ( $3-8$ psia) was substantially lower than the liquid vaporization pressure ( 13 psia @ 160 R). Vaporization within the dump system is now avoided with the addition of a LOX dump exit orifice. The orifice maintains the static pressure within the dump system above the vaporization pressure.

The LOX tank pressure is assumed to remain between 65 and 62 psi during the dump procedure. Figure 14 is a plot of simulated LOX mass flow rate as a function of dump system pressure differential.

The solid line represents a linear fit of the steady state simulation results. The LOX dump system performance can be described by the following equation, for tank pressures of $58-65 \mathrm{psi}$ and pressure differentials of $42-59 \mathrm{psi}$.

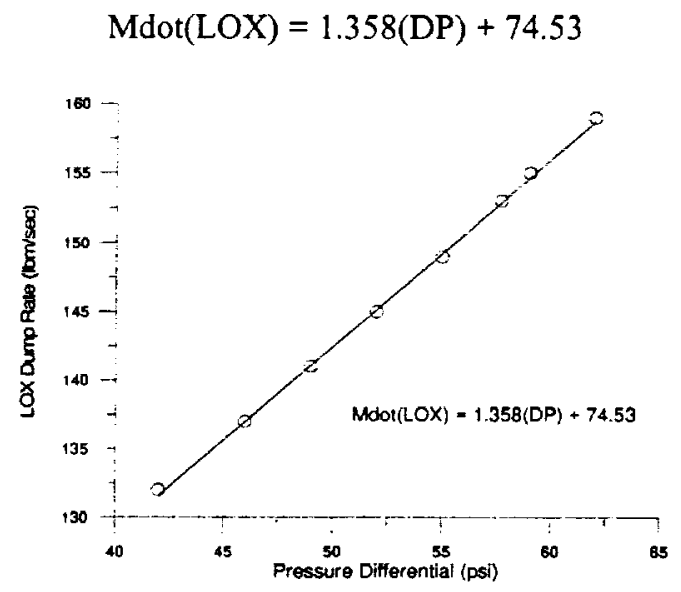

Figure 14 LOX Dump Flow Rate as a Function of Dump Exit Pressure

\section{RP-1 Dump System Model}

The RP-1 Dump system is primarily constructed of 3.5" ID line. The major components of the system include two 4" pneumatic valves and a Bernoulli type flow meter. The steady flow operation of the RP-1 dump system has also been simulated using GFSSP. Boundary conditions are set, corresponding to varying tank pressure and X-34 altitude during the X-34 abort trajectory. In some cases branch 
properties within the model are intentionally made conservative to ensure the actual system will meet the flow requirements.

The RP-I tank pressure will vary from 50 psi to 30 psi during the dump procedure. Figure 15 presents a plot of simulated RP-1 mass flow rate as a function of pressure differential between the tank and the dump system exit.

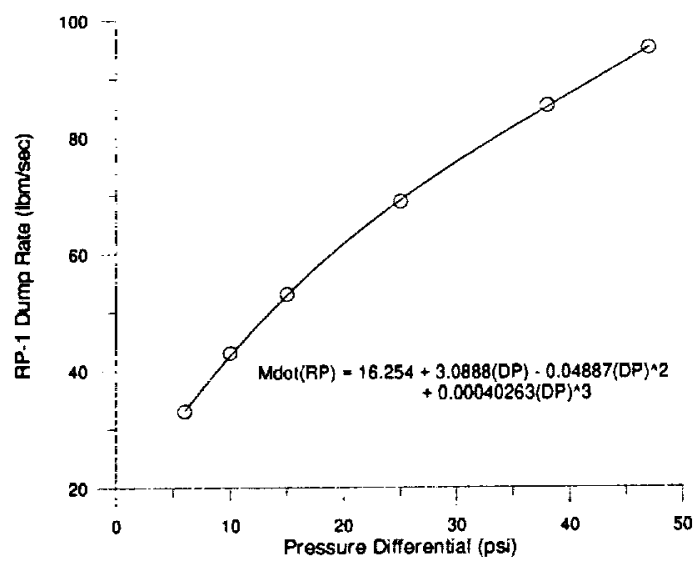

Figure 15 RP-1 Dump Mass Flow Rate as a Function of Pressure Differential

The solid curve represents a polynomial fit of the steady simulation results. The RP-1 dump system performance can be described by the following equation,

$$
\begin{aligned}
M \operatorname{dot}(\mathrm{RP})= & 16.254+3.0888(\mathrm{dP})-0.04887(\mathrm{dP})^{2} \\
& +0.00040263(\mathrm{dP})^{3}
\end{aligned}
$$

for pressure differentials of interest.

\section{Transient Dump Simulation}

The transient dump system simulation is performed by applying the transient boundary conditions, influenced by the simulated X-34 abort trajectory, to the functional relationships developed earlier. The LOX tank is pressurized to $62 \mathrm{psi}$ and the dump exit pressure varies with altitude. The RP-1 tank pressure is maintained at 50 psi until the tank is $50 \%$ empty, then the ullage gas is allowed to expand from 50 to $25 \mathrm{psi}$ at the completion of RP-1 dump. The LOX and RP-I propellant loads are assumed to be $21,064 \mathrm{lbm}$ and $9235 \mathrm{lbm}$ respectively. These values represent the propellant loads at the end of topping and are conservative because they include propellant that will be expelled prior to drop during turbopump chill and LOX conditioning procedures.
Figure 16 presents the transient propellant dump simulation results. The thin curve represents the remaining propellant mass if LOX is dumped first followed by RP-1. The thick curve represents the remaining propellant mass if $R P-1$ is dumped first followed by LOX. The dashed curve represents the $\mathrm{X}-34$ altitude.

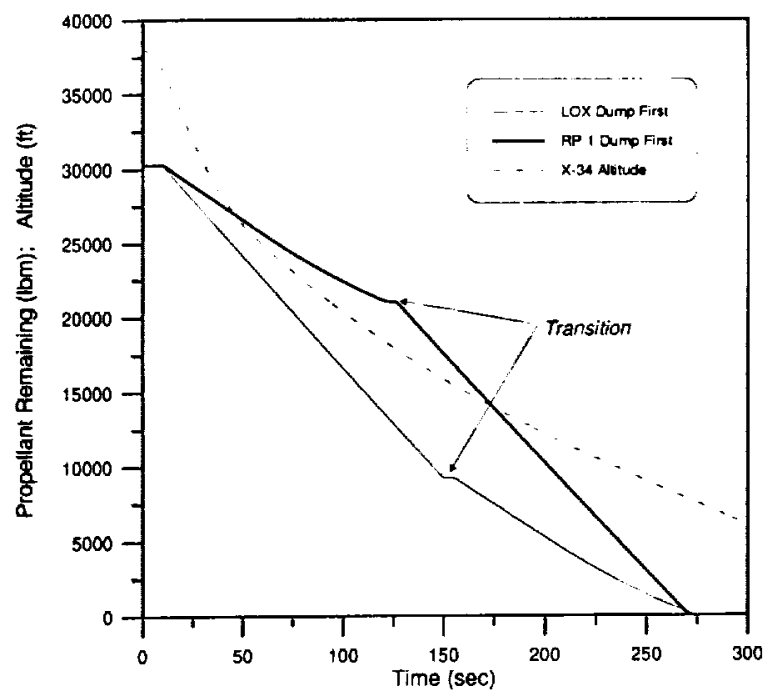

Figure $16 \quad \mathrm{X}-34$ Transient Dump System Simulation

In both cases, the dump procedure begins 10 seconds after the X-34 is dropped from the L1011. LOX dump takes $\sim 144$ seconds and the RP- 1 dump takes 117 seconds. There is a 4 second transition to account for valve operation etc. According to the simulated X-34 abort trajectory, the dump procedure will be complete by the time the X-34 vehicle descends to $\sim 7,500 \mathrm{ft}$. This simulation assumes $100 \%$ of the propellant mass must be dumped from the vehicle to be conservative. In reality some residuals $(<5 \%)$ will exist after dump.

\section{SUMMARY}

Analyses of the X-34 propellant management systems have been performed and presented. Simulations of the minimum LOX chill and fill time procedure indicate that LOX chill and fill will take at least 31 minutes due to vent line velocity constraints. LOX boil-off estimates predict that $716 \mathrm{lbm}$ of LOX will be lost during the conditioning phase of captive carry. Analyses of the vent/relief systems indicate that they are capable of expelling expected flows during normal operations as well as protecting the tanks against overpressurization resulting from a pressurization system failure. Propellant conditioning 
simulations indicate that the LOX temperature can be maintained to within the Fastrac engine start/Run box temperature range. RP-I can also be maintained within the Fastrac engine start/Run box temperature range. However, because RP-1 temperature at X-34 drop is a strong function of loading temperature, RP-1 temperatures must be controlled prior to ground loading of the X-34 tank. Propellant dump simulations indicate that the LOX dump will take 144 seconds and the RP-1 dump will take $\sim 117$ seconds. X-34 abort trajectory simulations indicate that the X-34 will be at an altitude of $\sim 7500$ at the completion of propellant dump.

\section{ACKNOWLEDGMENTS}

The authors would like to acknowledge Orbital and specifically Mr. Brian Winters for providing technical information and general support of the Main Propulsion System design. The authors also gratefully acknowledge Dr. Alok Majumdar for guidance in applying the Generalized Fluid System Simulation Program to X-34 MPS subsystem analysis and Mr. David Wood for gathering specific component performance information.

\section{REFERENCES}

1. Sgarlata, P., and Winters, B., "X-34 Propulsion System Design," $33^{\text {rd }}$ AIAA, SAE, ASME, ASEE Joint Propulsion Conference, AIAA \#97-3304, 1997

2. McDonald, J. P., Minor, R. B., Knight, K. C., Champion, R. H., and Russell, F. J., Jr., "Propellant Feed Subsystem for the X-34 Main Propulsion System,".34 $4^{\text {th }}$ AIAA, SAE, ASME, ASEE Joint Propulsion Conference, Cleveland Ohio, 1997

3. Hedayat, A., Steadman, T. E., Brown, T. M., Knight, K. C., White, C. E., and Champion, R. H. Jr., "Pressurization, Pneumatics, And Vent Subsystems of the X-34 Main Propulsion System," $34^{\text {th }}$ AIAA, SAE, ASME, ASEE Joint Propulsion Conference, Cleveland Ohio, 1997

4. Majumdar, A., "A Generalized Fluid System Simulation Program to Model Flow Distribution in Fluid Networks," Sverdrup Report No.: 331-201-96-003, October 1996 